\title{
Analysis on the Factors Related to the Accidental Pregnancy in 98 Teenage Girls
}

\author{
Yang Xu, Guixia Yang* \\ Gynecology, Dezhou Women and Children Hospital, Dezhou 253000, Shandong Province, China \\ *Corresponding author: Guixia Yang, 970237864@qq.com
}

\begin{abstract}
Objective: To understand the general information of adolescent girls with unplanned pregnancy and the information about abortion and reproductive health knowledge, analyze the influencing factors of unplanned pregnancy and explore the preventive measures. Methods: Using epidemiological investigation method, the adolescent females (age $<19$ years old) who volunteered requested pain deprivation in our hospital from January 2018 to December 2019 were examined by questionnaire with informed consultation, and the results were analyzed. Results: After screening, 98 valid questionnaires were received. The average age of girls were 16.81 years old, and the youngest was 13 years old. Employed girls accounted for 54.0\%, students for $23.5 \%$ and unemployed people for $22.5 \%$. Non-earners accounted for $38.8 \%$, and those with monthly income less than 3,000 yuan accounted for 86.8\%. 78.6 of those aged 16-18 had sex for the first time. The age of first sexual intercourse $\leq 15$ years old accounted for $21.4 \%$. The first abortion patients accounted for $84.7 \%$, repeated abortion accounted for $15.3 \%$. years old accounted for $19.05 \%$. First abortion in the age $\leq 15$ There was no statistical difference between the reproductive health knowledge mastery score and the family economic status, parents' occupation, parents' marital status, parents' sex education $(\mathrm{P}>0.05)$. The score of reproductive health knowledge was statistically different from that of school sex education and hospital sex education $(\mathrm{P}<0.05)$. Conclusions: The primary cause of unintended pregnancy is the lack of knowledge of contraception and reproductive health. Schools and hospitals are effective in sex education for adolescent girls. Relevant government departments, schools, families and hospitals should pay more attention to sex education and strengthen efforts to improve the quality of education, so as to further reduce the harm caused by accidental pregnancy of adolescent girls.
\end{abstract}

Keywords: Adolescent girls; Sex education; Accidental pregnancy; Abortion

Publication date: September 2021; Online publication: September 30, 2021

\section{Introduction}

With the progress of society, the first sexual life time of teenagers is ahead of schedule, and the rate of accidental pregnancy increases gradually, which seriously endangers the mental and physical health of girls. Therefore, it is necessary to give them correct education and guidance in time. In this study, the questionnaire was used to investigate the factors related to the unexpected pregnancy of adolescent girls, Analysis of the causes of unwanted pregnancies and explore preventive measures, reported below.

\section{Methods}

\subsection{Survey subjects}

From January 2018 to December 2019, our hospital asked for painless abortion (age <19).

\subsection{Contents of the survey}

Including the basic situation of patients, such as age, occupation, income, parental occupation, etc. The relevant information of reproductive information, such as the age of first sexual behavior, the age of first 
abortion, the commonly used contraceptive methods, the way of sexual education and publicity, etc. Fill out the questionnaire of reproductive health knowledge and calculate the score. The preparation, filling and input of the questionnaire are the responsibility of the abortion operating room, and the corresponding quality control is adopted.

\subsection{Statistical methods}

The questionnaire number, double input and check, using EpiData 3.1 software to establish database, using Excel and SPSS 22.0 software for data analysis, using chi-square test and rate comparison for statistical analysis, $\mathrm{P}<0.05$ shows that the difference is statistically significant.

\section{Results}

\subsection{General}

The minimum age was 13 and the maximum was $18 \leq 15.3$ per cent, and 84.7 per cent, The average age was 16.81 years. $54.0 \%$ of employed persons, $23.5 \%$ of students. The proportion of unemployed people are $22.5 \% .38 .8 \%$ of persons without income. A monthly income of $<3000$ yuan accounted for 86.8 yuan. $38.0 \%$ of unwanted pregnant girls cohabiting with their sexual partners. The minimum age of a sexual partner is 14, up to 27 . The average age is 18.22 years. $38.7 \%$ live with classmates/friends, $23.3 \%$ live with their parents. The top three parents are farmers, workers and individuals. The proportion of parents in a harmonious marriage was $86.7 \%$. The proportion of marital discord is $10.2 \%$. The proportion of unclear marital status of parents was $3.1 \%$.

\subsection{Abortion and contraception}

The number of persons aged 16 to 18 years of initial sexual intercourse was $77,78.6 \%$. For the first time $\leq$ the age of 15 was $21,21.4 \%$. The number of first-time abortions was $83,84.7 \%$. For the first time $\leq 15$ years of age, $19.05 \%$. There were 15 repeat abortions, $15.3 \% \leq 0$ repeat abortions at the age of 15 . The number of repeated abortions was 1 . Four people $\leq$ three months apart from this abortion, $26.7 \%$ of repeat abortions. The remaining 11 people and this abortion interval is within a year. The main cause of this accidental pregnancy was $1.31 .1 \%$ of the total number of people who have never taken contraception, Contraceptive failure accounted for $68.9 \%$. Contraceptive losers use mainly condoms, extracorporeal ejaculation, emergency contraceptives and etc.

\subsection{Premarital sexual attitudes}

In this study, $35.7 \%$ of accidental pregnancy girls thought that premarital sex should not be performed at any time, $37.8 \%$ of accidental pregnancy girls thought that premarital behavior could be performed if they were to marry the man, and $26.5 \%$ of accidental pregnancy girls thought that if they had feelings with the man, they could have premarital sex.

\subsection{Reproductive health knowledge score}

$42.9 \%$ of girls with unwanted pregnancies had active access to reproductive health knowledge and $57.1 \%$ had no active access to reproductive health knowledge.

The girls were divided into two groups according to different scores. The A group scored 4-14 ( $n=43)$ and the B group scored 15-24 ( $\mathrm{n}=55)$. The main sources of reproductive health knowledge available to adolescent girls during unwanted pregnancies are schools, parents, hospitals and networks. According to chi-square test analysis, father's occupation had nothing to do with the score of reproductive health knowledge $\left(\mathrm{X}^{2}=7.395, \mathrm{P}=0.286\right)$, mother's occupational and reproductive health knowledge score $(\mathrm{X})$ was $\left.\mathrm{X}^{2}=12.435, \mathrm{P}=0.133\right)$, parents' marital status was not related to reproductive health knowledge score $(\mathrm{X})$; 
$\mathrm{X}^{2}=2.545, \mathrm{P}=0.280$ ), parental sex education had nothing to do with reproductive health knowledge score $\left.(\mathrm{X}) ; \mathrm{X}^{2}=0.677, \mathrm{P}=0.173\right)$, school propaganda related to reproductive health knowledge score $(\mathrm{X}) ; \mathrm{X}^{2}=4.482$, $\mathrm{P}=0.034)$, hospital publicity related to reproductive health knowledge score $\left.(X) ; X^{2}=5.252, P=0.022\right)$. See

Table 1. for details.

Table 1. Factors related to reproductive health knowledge score

\begin{tabular}{|c|c|c|c|c|c|}
\hline & \multicolumn{2}{|c|}{$\begin{array}{l}\text { Reproductive health knowledge } \\
\text { score }\end{array}$} & \multirow{2}{*}{ Total } & \multirow{2}{*}{$P$} & \multirow{2}{*}{$X^{2}$} \\
\hline & $\begin{array}{l}\text { A group (4-14, } \\
n=43)\end{array}$ & $\begin{array}{l}\text { B group }(15-24, \\
n=55)\end{array}$ & & & \\
\hline \multicolumn{6}{|l|}{ Father's occupation } \\
\hline Individual & 5 & 15 & 20 & & \\
\hline Workers & 16 & 13 & 29 & & \\
\hline Institutions and institutions & 0 & 2 & 2 & & \\
\hline Teachers & 1 & 0 & 1 & & \\
\hline Farmers & 17 & 20 & 37 & & \\
\hline Other & 2 & 3 & 5 & & \\
\hline Staff & 2 & 2 & 4 & 0.286 & 7.395 \\
\hline \multicolumn{6}{|l|}{ Mother's occupation } \\
\hline Individual & 4 & 15 & 19 & & \\
\hline Workers & 12 & 9 & 21 & & \\
\hline Institutions and institutions & 0 & 2 & 2 & & \\
\hline Teachers & 0 & 1 & 1 & & \\
\hline Farmers & 17 & 16 & 33 & & \\
\hline Other & 1 & 4 & 5 & & \\
\hline Unemployed & 5 & 6 & 11 & & \\
\hline Doctors & 2 & 0 & 2 & & \\
\hline Staff & 2 & 2 & 4 & 0.133 & 12.435 \\
\hline \multicolumn{6}{|l|}{ Parental status } \\
\hline Disparity & 4 & 6 & 10 & & \\
\hline Not clear & 0 & 3 & 3 & & \\
\hline Harmony & 39 & 46 & 85 & 0.280 & 2.545 \\
\hline \multicolumn{6}{|l|}{ Parent sex education } \\
\hline Yes & 28 & 38 & 66 & & \\
\hline Not taught & 15 & 17 & 32 & 0.677 & 0.173 \\
\hline \multicolumn{6}{|l|}{ School sex education } \\
\hline Not yet & 16 & 10 & 26 & & \\
\hline Access & 27 & 45 & 72 & 0.034 & 4.482 \\
\hline \multicolumn{6}{|l|}{ Hospital sex education } \\
\hline Not yet & 24 & 18 & 42 & & \\
\hline Access & 19 & 37 & 56 & 0.022 & 5.252 \\
\hline Total & 43 & 55 & 98 & & \\
\hline
\end{tabular}




\section{Discussion}

In recent decades, family planning services in China have made great achievements, but the past service focuses on married women of childbearing age, and the attention to unmarried teenagers is relatively small. With the development of society, the age of marriage and childbearing in our country is gradually delayed, which is contrary to the sexual physiological needs of teenagers, resulting in the increase of the number of accidental pregnancies of young girls in our country year by year ${ }^{[1-2]}$. According to statistics, there are about 15 million young girls giving birth every year, accounting for $20 \%$ of the world's total births, and the pregnancy rate of young girls in China is $3 \%$, and the annual rate of increase is $6.9 \%$ [3]. Unforeseen pregnancy for young girls brings not only a heavy economic burden to society and family, but also a great harm to the physical and mental health of pregnant girls. Improving adolescent reproductive health literacy and reducing the rate of unwanted pregnancies among adolescent girls is a major focus of current research $[4,5]$.

\subsection{Characteristics of adolescent girls with unwanted pregnancies}

In this survey, the minimum age was 13 years and the average age was 16.81 years. It is suggested that one of the main causes of accidental pregnancy is the age of primary sexual life. Although $54.0 \%$ of the employed population, the proportion of monthly income $<3000$ yuan is $86.8 \%$, the income is on the low side and is not yet adult, which indicates that the education level is low. The above characteristics are consistent with the results of many other studies ${ }^{[6-8]}$.

\subsection{Factors related to accidental pregnancy in adolescent girls}

Parents are the first teachers of children, and family sex education has a profound impact on adolescent sexual behavior. Many foreign literature reports that effective family sex education can effectively delay the age of first sexual behavior and reduce dangerous behavior ${ }^{[9-11]}$. Under the influence of conservative culture, the content of sex education given by Chinese parents to teenagers is relatively narrow and the effect is poor ${ }^{[12]}$. In this survey, the top three parents are farmers, workers and individuals, which reflects that the educational level of adolescent parents in this survey is relatively low, but from the relationship between parental sex education and adolescent reproductive health knowledge score, although the impact is small, the effect of visibility education is not ideal, may also be related to the small sample size ${ }^{[13]}$. Although most rural parents advocate adolescent sex education, their own knowledge is limited, they cannot say the specific contents that should be taught, and the ability to give adolescent sex education is limited, which is consistent with the results of this study. Sex education among left-behind young people in rural areas is more worrying. Studies have found that they have different degrees of psychological disorders and lower levels of sexual mental health ${ }^{[14]}$.

Through the investigation of primary and secondary schools in Yongchuan District of Chongqing, it is found that only $22.4 \%$ of primary and secondary schools have youth sex education courses ${ }^{[15]}$. The huge sex education teacher gap cannot be filled in a short time, most of the domestic teachers for other subjects, students to the current school sex education recognition is low ${ }^{[16]}$. In this study, $73.5 \%$ of adolescents received sex education in schools, which is higher than other studies in China ${ }^{[15,17]}$. However, the quality of visibility education needs to be improved.

In this survey, $72.1 \%$ of girls with unwanted pregnancies did not use contraception, while $27.9 \%$ did not use proper contraception, such as in vitro ejaculation, safe period contraception, oral emergency contraception and so on. According to the score of the questionnaire of reproductive health knowledge, the adolescent girls who received the survey did not have enough knowledge of contraception, and did not have enough understanding of the harm caused by abortion, which was similar to other domestic survey results $[18,19]$. 
At present, the government distributes contraceptives free of charge mainly for women of childbearing age, but not for adolescents and unmarried women. The proportion of employed people in the survey was 54.1 , but the income was on the low side. The proportion of students is 23.47 , the proportion of unemployed people is 22.5, and the proportion of those without income is 38.8. Some people do not know enough about contraception, coupled with limited economic level, fluke psychology without contraception, resulting in accidental pregnancy.

\subsection{Discussion on measures to reduce the incidence of accidental pregnancy among adolescent girls}

The relevant government departments can further deepen the reform of the education system, increase the inclination of the education subsidy policy, expand the teaching staff, and strictly assess the work of sex education, and set up measures of rewards and punishments. Raise adolescent sex education to a new level of improving national quality and protecting reproductive health. The relevant departments of health administration can set up the Society of Reproductive Health Education and hold relevant training courses. The media departments can cooperate with the government to do a good job in sex education and propaganda, and combine with TV related health education programs to carry out propaganda and education. Schools should include subjects related to sex education in the syllabus, train professional teachers, regularly assess and evaluate relevant professional teachers, and test the reproductive health knowledge of young students. We can refer to the methods and methods of sex education in developed countries, take its essence and formulate sex education policies in accordance with our national conditions. In addition, the school can take the lead to set up the parents' school of reproductive health education, make up for the lack of parents' knowledge of reproductive health education, teach them the correct way to communicate with their children, and improve the knowledge level of parents' reproductive health.

Expand the coverage of adolescent girls in the family planning sector, with a focus on adolescents who have dropped out of school and avoid omissions in reproductive health information. Family planning departments can expand the distribution of free contraceptives to this part of the population, reducing their financial burden. Studies on post-abortion care (PAC) among adolescents show that PAC can effectively increase the rate of correct contraception among adolescents and reduce the incidence of repeated abortions ${ }^{[6,20]}$. We should focus on strengthening PAC construction and expanding the scope of PAC services. Hospitals should fully PAC the role of psychological comfort to girls with accidental pregnancy, at the same time, to popularize abortion related hazards and contraceptive knowledge, improve the follow-up rate of this part of the population, implement contraceptive measures, and reduce the rate of repeated abortion. Adolescents should be encouraged to implement long-acting reversible contraceptive methods (LARCs, long-acting reversible contraceptive), such as intrauterine devices and subcutaneous implants. In addition, adolescents should focus on the importance of safe sex to prevent the spread of sexually transmitted diseases such as AIDS, syphilis and so on.

Accidental pregnancy of adolescent girls is a topic of great concern in society. The present situation of accidental pregnancy of adolescent girls is not optimistic. The physical and mental health of teenagers is related to our future. It helps teenagers to establish correct sexual concepts, improve their knowledge of reproductive health, and avoid unnecessary harm.

\section{Disclosure statement}

The author declares no conflict of interest.

\section{References}

[1] Leftwich HK, Alves MO. 2017, Adolescent Pregnancy. Pediatr Clin North Am, 64(2):381-388. 
[2] Cai H, 2017, Advances in the Study of Adolescent Contraceptive Methods at Home and Abroad. Chinese Journal of Family Planning, 25(03):209-213.

[3] Mrug S, Elliott MN, Davies S, et al., 2014, Early Puberty, Negative Peer Influence, and Problem Behaviors in Adolescent Girls. Pediatrics, 133(1):7-14.

[4] He X, Xu H, 2019, Adolescent Pregnancy and Contraception. Family Planning, Obstetrics and Gynecology in China, 11(11):14-16.

[5] Qin M, Deng J, et al., 2018, A Survey of Contraceptive Knowledge Related to Teenage Pregnancy. Accidental Pregnancy Chinese Journal of Family Planning, 26(09):780-783.

[6] Ji F, Li H, et al., 2018, Analysis of the Current Situation of 1638 Induced Abortion Adolescents and Follow-Up Study on the Implementation of Post-Abortion Care. Chinese General Medicine, 17(01):91-94.

[7] Zhang Bin, et al., 2017, Analysis on the Current Situation and Influencing Factors of Abortion Among Young Women in Tai' an City. China Maternal and Child Health Care, 32(17):4235-4238.

[8] Han L, et al., 2019, Survey on Sexual and Reproductive Health Knowledge, Attitudes, Behaviour of Adolescents Aged 15 and 21 Years By Sex. Guangdong Medicine, 40(S1):187-189+192.

[9] Widman L, et al., 2016, Parent-Adolescent Sexual Communication and Adolescent Safer Sex Behavior: A Meta-Analysis. JAMA Pediatrics, 170(1):52-61.

[10] Silk J, Romero D, 2014, The Role of Parents and Families in Teen Pregnancy Prevention: An Analysis of Programs and Policies. J Fam Issues, 35(10):1339-1362.

[11] Wang NX, 2016, Parent-Adolescent Communication About Sexuality in Chinese Families. J Fam Commun, 16(3):229-246.

[12] Liu T, Fuller J, Hutton A, 2017, Consequence-Based Communication about Adolescent Romantic Experience Between Parents and Adolescents : A Qualitative Study Underpinned by Social Constructionism. Nursing \& Health Sciences, 19(2): 176-182.

[13] Tu X, et al., 2018, Attitude and Views of Parents on Sexuality Education for Disabled Adolescents, International Journal of Reproductive Health/Family Planning, 37(05):357-359+371.

[14] Li G, Liu Y, Hu J, 2017, Analysis on the Present Situation of Sexual Psychology in Rural Leftbehind Adolescents and Its Influencing Factors. Chinese Sex Science, 26(08):146-150.

[15] Xiao J, et al., 2017, Analysis on Present Situation and Countermeasure of Adolescent Sexual Health Education in Yongchuan District of Chongqing. China Chongqing Medical Science. (30):4301-4303.

[16] Chen S, et al., 2016, Investigation on the Present Situation and Countermeasure of Adolescent Sex Education in Zhongshan City. Chinese Sex Science, 25(01):132-136.

[17] Wu J, et al., 2019, A Survey of Sexual and Reproductive Health Education in Secondary Schools. Needs Analysis Chinese Sex Science, 28(02):149-153.

[18] Duan X, et al., 2020, A Survey of Sexual Behavior and Contraception Status of Abortion Girls. Chinese Journal of Family Planning, 20(12):822-824+831.

[19] Zheng W, 2019, Adolescent Sexuality and Sexuality Education. China Family Planning and Obstetrics and Gynecology, 11(11):6-7+16.

[20] Wang F, 2020, Global Consensus Statement to Promote the Choice of Long-Lasting Reversible Contraceptive Methods Among Adolescents. Chinese Journal of Family Planning, 24(9):646-648. 